\title{
Broncopneumonia causada por Arcanobacterium pyogenes em Veado Campeiro (Ozoteceros bezearticus).
}

\author{
Bronchopneumonia caused by Arcanobacterium pyogenes in Pampas Deer (Ozoteceros bezearticus). \\ Joelma Lucioli', Fernando Henrique Furlan'1, Denis Augusto Spricigo², Sandra Maria Ferraz ${ }^{2}$ \& Sandra \\ Davi Traverso'
}

\begin{abstract}
RESUMO
Arcanobacterium pyogenes é uma bactéria comensal das membranas mucosas do trato respiratório e genital de várias espécies de animais domésticos e selvagens. Porém, em decorrência de estresse ou traumatismos, A. pyogenes pode se tornar um patógeno oportunista, associado a infecções supurativas. Estresse é um importante fator de risco para doenças em todos os animais, mas especialmente em animais silvestres não habituados ao contato humano. Um veado-campeiro (Ozoteceros bezearticus) criado em área conservacionista, foi encontrado prostado e demonstrando dificuldades respiratórias. Este animal foi encaminhado ao Hospital de Clínica Veterinária - CAV/UDESC, onde recebeu tratamento, mas, dois dias após, morreu. O exame microscópico dos pulmões revelou áreas focalmente extensas de necrose associada a infiltrado moderado de polimorfonucleares, circundados por tecido fibroso. De acordo com a necropsia, cultivo microbiológico e seqüenciamento de DNA, o agente envolvido foi classificado como A. pyogenes, caracterizando o primeiro relato de Broncopneumonia causada por A. pyogenes em Veado-Campeiro (Ozoteceros bezearticus) no Brasil.
\end{abstract}

Descritores: Broncopneumonia, Arcanobacterium pyogenes, doença respiratória, cervídeo, Brasil.

\section{ABSTRACT}

Arcanobacterium pyogenes is a commensal bacteria of the mucous membranes of the respiratory and genital tracts of a number of domestic and wildlife animal species. However, following a stress or traumatic insults, A. pyogenes can become an opportunistic pathogen, associated with suppurative infections. Stress is an important risk factor for disease in all animals but especially in wild animals unaccustomed to human contact. A Pampas Deer (Ozoteceros bezearticus) fed in a conservation area, was found prostated and showing respiratory difficulties. This animal was taken to the Veterinary Clinical Hospital - CAV/ UDESC, where it was treated but died two days later. Microscopic examination of lungs revealed areas focally extensive of necrosis associated with moderate infiltrates of polymorphonuclear surrounded by fibrous tissue. According to necropsy, microbiological cultive and DNA sequencing, the agent was classified as A. pyogenes. Characterizing the first reported case of Bronchopneumonia caused by A. pyogenes in Pampas Deer (Ozoteceros bezearticus) in Brazil.

Key words: Bronchopneumonia, Arcanobacterium pyogenes, respiratory disease, Cervidae, Brazil.

${ }^{1}$ Departamento de Medicina Veterinária, Laboratório de Patologia Animal, Centro de Ciências Agroveterinárias (CAV) - UDESC, Lages, SC/ Brasil. ${ }^{2}$ Departamento de Medicina Veterinária, Laboratório de Microbiologia, CAV/UDESC. CORRESPONDÊNCIA: S.D. Traverso [a2sdt@cav.udesc.br]. 


\section{INTRODUÇÃO}

Arcanobacterium pyogenes é uma bactéria Gram-positiva pleomórfica [3], que produz uma exotoxina hemolítica dermonecrótica, uma protease e uma Dnase, responsáveis por causar uma variedade de infecções supurativas envolvendo pele, articulações e órgãos [6]. Geralmente, a infecção é autógena e consequiência de uma lesão na mucosa oral [7]. Em cervídeos, Arcanobacterium pyogenes tem sido implicado em mastite [11], abscessos intracraniais [1,9], abscessos de pés [8], metrites, endocardites e abortos [10]. Este trabalho tem o objetivo de descrever o primeiro relato brasileiro de broncopneumonia em veado-campeiro (Ozotoceros bezoarcticus) causado por Arcanobacterium pyogenes.

\section{RELATO DE CASO}

Um veado-campeiro (Ozotoceros bezoarcticus), macho, criado em uma reserva conservacionista, foi encontrado prostrado e com dificuldade respiratória. O animal foi encaminhado ao Hospital de Clínicas Veterinárias CAV/UDESC, onde recebeu tratamento à base de enrofloxacina $10 \%$, ketoprofeno $1 \%$ e Ringer Lactato glicose 5\%. Após dois dias, morreu e foi encaminhado ao Laboratório de Patologia Animal, onde o animal foi necropsiado e amostras foram coletadas para histopatologia e microbiologia.

Para histopatologia, as amostras foram conservadas em formol a $10 \%$ e processadas rotineiramente para Hematoxilina \& Eosina e coloração de Gram. O cultivo microbiológico foi feito em meio de

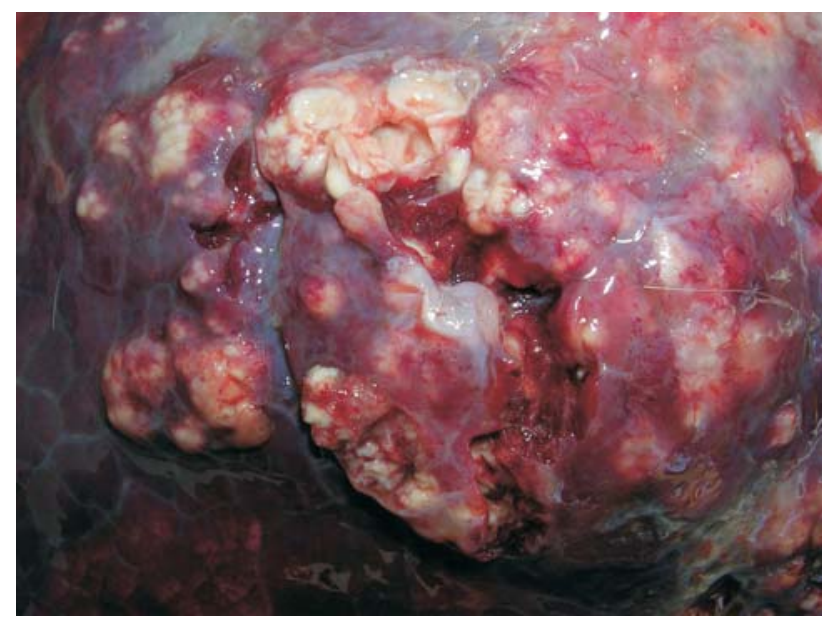

Figura 1. Broncopneumonia por Arcanobacterium pyogenes. Veado Campeiro. Pulmões vermelhos, consolidados e com abscessos múltiplos. ágar sangue em anaerobiose e para o seqüenciamento foram utilizados primers universais para DNA ribossomal bacteriano confeccionados e amplificados conforme Fredricks \& Relman (1998); submetidos ao seqüenciamento de DNA utilizando um seqüenciador automático de DNA (Megabace, Amershan Bioscience) e Kit (Dye Terminator, Amershan Bioscience). As seqüências obtidas foram analisadas qualitativamente com o programa Staden e comparadas com as presentes no GenBank [2], utilizando o programa BLASTn.

À necropsia, observou-se traquéia hiperêmica e com fibrina; efusão pleural fibrinopurulenta; pulmões vermelhos, consolidados, com abscessos múltiplos e áreas de aderência pleural (Figura 1). $\mathrm{Na}$ histologia, revelou necrose pulmonar focalmente extensa, associada a infiltrado polimorfonuclear moderado, circundada por tecido fibroso. Na coloração de gram, colônias Gram positivas eram evidenciadas nas áreas de necrose. No cultivo microbiológico observou-se, quatro dias após a semeadura, crescimento de colônias muito pequenas B-hemolíticas (Figura 2), que, pela microscopia, demonstravam ser cocobacilos Gram positivos, dispostos em um arranjo "em paliçada", também denominado "letras chinesas". A sequiência obtida foi de $97 \%$ de identidade quando comparada à sequiência gil1838947 lemb|x79225.11ap16srr armazenada no GenBank, que foi reconhecida como A. pyogenes, admitindo $\mathrm{e}=0,0$.

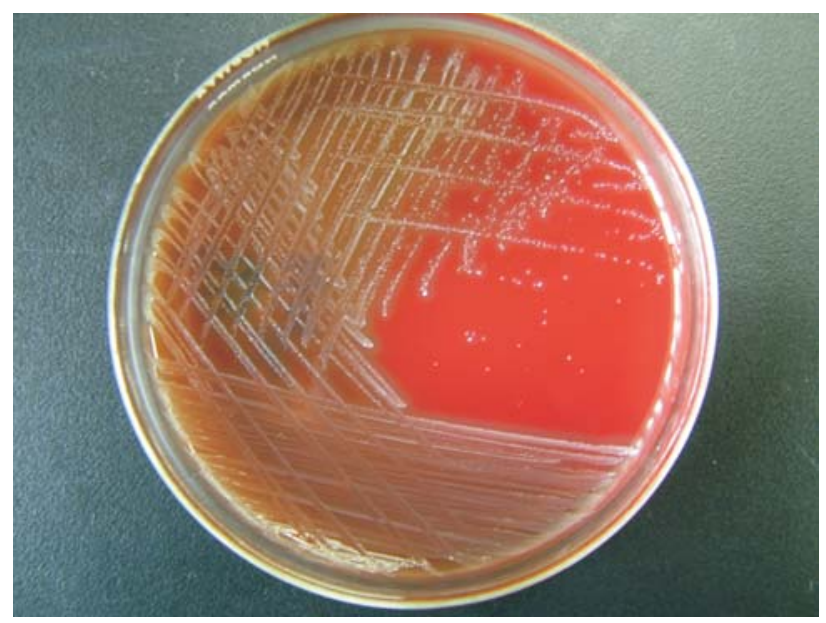

Figura 2. Broncopneumonia por Arcanobacterium pyogenes. Veado Campeiro. Cultivo microbiológico em meio de ágar sangue em anaerobiose, crescimento de colônias muito pequenas $\beta$-hemolíticas. 


\section{DISCUSSÃO}

Pneumonia abscedativa por Mycoplasma bovis foi descrita em cervídeos criados em cativeiro [4], mas as lesões histológicas e cultivo bacteriano diferem do observado nesse caso. A. pyogenes é bactéria comensal das mucosas de animais saudáveis, sendo a prevalência da doença esporádica determinada pela ocorrência de estresse ou lesão traumática [3]. O estresse é um fator de risco muito importante para várias doenças, principalmente de animais selvagens. Ele pode ser determinado por várias causas, incluindo captura, transporte, desmame, nutrição deficiente e mudanças nas estruturas sociais ou climáticas [10]. Nesse caso, a ausência de infecções primárias sugere que o estresse teve papel significativo no desenvolvimento da doença.

De acordo com as características de colônia, coloração de Gram, bioquímica e seqüenciamento de DNA, o agente foi identificado como A. pyogenes.

Agradecimentos. A Élgio L.S. Loreto, do Laboratório de Drosófilas (LABDROS) e Agueda P.C. de Vargas, do Laboratório de Bacteriologia (LABAC), ambos da Universidade Federal de Santa Maria (UFSM), pelo seqüenciamento das amostras.

\section{REFERÊNCIAS}

1 Baumann C.D., Davidson W.R. \& Roscoe D.E. 2001. Intracranial abscessation in white-tailed deer of North America. Journal of Wildlife Diseases. 37: 661-670.

2 Benson D. A., Karsch-Mizrachi I., Lipman D.J., Ostell J., Rapp B.A. \& Wheeler D.L. 2002. GenBank. Nucleic Acids Research. 30: 17-20.

3 Biberstein E.L. \& Hirsh D.C. 1999. Corinebactérias; Arcanobacterium (Actinomyces) pyogenes; Rhodococcus equi. In: Hirsh D.C. \& Zee Y.C. (Eds). Microbiologia Veterinária. Rio de Janeiro: Guanabara, pp.119-126.

4 Dyer N.W., Krogh D.F. \& Schaan L.P. 2004. Pulmonary mycoplasmosis in farmed white-tailed deer (Odocoileus virginianus). Journal of Wildlife Diseases. 40: 366-370.

5 Fredricks D.N. \& Relman D.A. 1998. Sequencing of DNA bacteria by universal 16Sr DNA PCR. Journal of Clinical Microbiology. 36: 2810-2816.

6 Jost B.H. \& Billington S.J. 2004. Corynebacterium and Arcanobacterium. In: Gyles C.L., Prescott J.F. \& Songer J.G. (Eds). Pathogenesis of bacterial infections in animals. 3rd edn. Ames: Blackwell, pp.77-86.

7 Jost B.H. \& Billington S.J. 2005. Arcanobacterium pyogenes: molecular pathogenesis of an animal opportunist. Antonie van Leeuwenhoek. 88: 87-102.

8 Lavín S., Ruiz-Bascarán M. \& Marco I. 2004. Foot infections associated with Arcanobacterium pyogenes in free-living fallow deer (Dama dama). Journal of Wildlife Diseases. 40: 607-611.

9 Nettles V.F., Quist C.F. \& Lopez R.R. 2002. Morbidity and mortality factors in key deer (Odocoileus virginianus clavium). Journal of Wildlife Diseases. 38: 685-692.

10 Palmer M.V. \& Whipple D.L. 1999. Arcanobacterium pyogenes as a cause of fatal pleuropneumonia after capture and transport of white-tailed deer (Odocoileus virginianus). Journal of Veterinary Diagnostic Investigation. 11: 468-471.

11 Turnquist S.E. \& Fales W.H. 1998. Disseminated Actinomyces pyogenes infection in a free-ranging white-tailed deer. Journal of Veterinary Diagnostic Investigation. 10: 86-89.

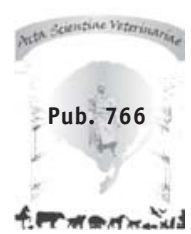

